ACCEPTED MANUSCRIPT

\title{
IPEM Topical Report: A 2018 IPEM survey of MRI use for external beam radiotherapy treatment planning in the UK
}

To cite this article before publication: Richard Speight et al 2019 Phys. Med. Biol. in press https://doi.org/10.1088/1361-6560/ab2c7c

\section{Manuscript version: Accepted Manuscript}

Accepted Manuscript is "the version of the article accepted for publication including all changes made as a result of the peer review process, and which may also include the addition to the article by IOP Publishing of a header, an article ID, a cover sheet and/or an 'Accepted

Manuscript' watermark, but excluding any other editing, typesetting or other changes made by IOP Publishing and/or its licensors"

This Accepted Manuscript is (c) 2019 Institute of Physics and Engineering in Medicine.

During the embargo period (the 12 month period from the publication of the Version of Record of this article), the Accepted Manuscript is fully protected by copyright and cannot be reused or reposted elsewhere.

As the Version of Record of this article is going to be / has been published on a subscription basis, this Accepted Manuscript is available for reuse under a CC BY-NC-ND 3.0 licence after the 12 month embargo period.

After the embargo period, everyone is permitted to use copy and redistribute this article for non-commercial purposes only, provided that they adhere to all the terms of the licence https://creativecommons.org/licences/by-nc-nd/3.0

Although reasonable endeavours have been taken to obtain all necessary permissions from third parties to include their copyrighted content within this article, their full citation and copyright line may not be present in this Accepted Manuscript version. Before using any content from this article, please refer to the Version of Record on IOPscience once published for full citation and copyright details, as permissions will likely be required. All third party content is fully copyright protected, unless specifically stated otherwise in the figure caption in the Version of Record.

View the article online for updates and enhancements. 


\section{IPEM Topical Report: A 2018 IPEM survey of MRI use for external beam radiotherapy treatment planning in the UK}

\section{Author list:}

Richard Speight, Leeds Cancer Centre, Leeds Teaching Hospitals NHS Trust, Leeds, UK

Maria A. Schmidt, Royal Marsden NHS Foundation Trust and Institute of Cancer Research, London, UK

Gary Liney, Ingham Institute for Applied Medical Research \& Liverpool Cancer Therapy Centre, Liverpool, Sydney, NSW 2170, Australia

Robert Johnstone, Guy's and St. Thomas' NHS Foundation Trust, London, UK

Cynthia L Eccles, The Christie NHS Foundation Trust and the University of Manchester, Manchester, UK

Michael Dubec, The Christie NHS Foundation Trust and the University of Manchester, Manchester, UK

Ben George, Department of Oncology, University of Oxford, Oxford, UK

Ann Henry, Leeds Cancer Centre, Leeds Teaching Hospitals NHS Trust and University of Leeds, Leeds, UK

Hazel McCallum, Northern Centre for Cancer Care, Newcastle upon Tyne Hospitals NHS Foundation Trust, Newcastle upon Tyne, UK

\section{Conflict of interest:}

none

\section{Keywords}

Audit, Survey, MRI, radiotherapy, UK 


\begin{abstract}
Introduction/Background:
\end{abstract}

The benefits of integrating MRI into the radiotherapy pathway are well published, however there is little consensus in guidance on how to commission or implement its use. With a view to developing consensus guidelines for the use of MRI in external beam radiotherapy (EBRT) treatment planning in the UK, a survey was undertaken by an Institute of Physics and Engineering in Medicine (IPEM) working-party to assess the current landscape of MRI use in EBRT in the UK.

Methods:

A multi-disciplinary working-party developed a survey to understand current practice using MRI for EBRT treatment planning; investigate how MRI is currently used and managed; and identify knowledge gaps. The survey was distributed electronically to radiotherapy service managers and physics leads in 71 UK radiotherapy (RT) departments (all NHS and private groups).

Results:

The survey response rate was $87 \%$ overall, with $89 \%$ of NHS and $75 \%$ of private centres responding. All responding centres include EBRT in some RT pathways: $94 \%$ using Picture Archiving and Communication System (PACs) images potentially acquired without any input from RT departments, and $69 \%$ had some form of MRI access for planning EBRT. Most centres reporting direct access use a radiology scanner within the same hospital in dedicated (26\%) or non-dedicated (52\%) RT scanning sessions. Only two centres reported having dedicated RT MRI scanners in the UK, lower than reported in other countries. Six percent of radiotherapy patients in England (data not publically available outside of England) have MRI as part of their treatment, which again is lower than reported elsewhere. Although a substantial number of centres acquire MRI scans for treatment planning purposes, most centres acquire less than five patient scans per month for each treatment site. Commissioning and quality assurance of both image registration and MRI scanners was found to be variable across the UK. In addition, staffing models and training given to different staff groups varied considerably across the UK, reflecting the current lack of national guidelines.

Conclusion:

The primary barriers reported to MRI implementation in EBRT planning included costs (e.g., lack of a national tariff for planning MRI), lack of MRI access and/or capacity within hospitals. Despite these challenges, significant interest remains in increasing MRI-assisted EBRT planning over the next five years. 


\section{Introduction}

Due to its superior soft-tissue discrimation, compared to computed tomography (CT), magnetic resonance imaging (MRI) has been used as a tool in external beam radiotherapy (EBRT) to aid in the delineation of tumours and normal tissues since the mid-1980s (Curran et al 1986, Rai et al 2017, Kupelian and Sonke 2014, Raaymakers et al 2009, Pollard et al 2017). The benefits of MRI within EBRT have been evidenced in many tumour sites including the brain (Beavis et al 1998), head and neck (Močnik et al 2018, Liney et al 2013), breast (Shang et al 2017, Giezen et al 2011), prostate (Ménard et al 2018), cervix (Metcalfe et al 2013) and liver (Voroney et al 2006, van de Lindt et al 2016). The inability to distinguish tumour from normal tissues on $\mathrm{CT}$ in the abdomen has led to a recent increase in interest in abdominal MRI for EBRT treatment planning, with 4D MRI suggested as a motion management strategy (Paganelli et al 2018b, Stemkens et al 2018).

In addition to anatomical information, MRI allows the ability to undertake multiparametric imaging within a single appointment slot. Specifically functional MRI (defined here in the context of EBRT as non-anatomical imaging that is used to assess physiology, such as diffusion weighted imaging (DWI) and dynamic contrast enhanced (DCE) imaging) adds to the information offered by $\mathrm{CT}$ for accurate target and normal tissue delineation in radiotherapy $(\mathrm{RT})$ treatment planning.

The American Association of Physicists in Medicine (AAPM) Task Group (TG-101) (Benedict et al 2010) on stereotactic body radiotherapy (SBRT or SABR) states that MRI is a goldstandard for visualization of brain tumours and is "increasingly used in SBRT applications including prostate, spinal tumours, chest, and solid abdominal tumours". With the development and clinical implementation of hybrid MRI-RT delivery devices (Mutic and Dempsey 2014, Keall et al 2014, Fallone 2014, Lagendijk, J J W, Raaymakers, B W, van Vulpen 2014), the impetus for more centres to routinely use MRI in RT planning continues to grow (Erler et al 2018, Glide-hurst et al 2016).

There are, however, well reported challenges to clinical implementation of MRI for EBRT treatment planning, including: assessment and assuring geometric fidelity; integration and compatibility of a flat-couch top and lasers; assessment and management of image registration errors; and the additional costs to train and resource staff.

Even though there are arguments for MRI to be integrated into a CT workflow for EBRT treatment planning and a growing interest in the potential of MRI-only treatment pathways (Edmund and Nyholm 2017, Johnstone et al 2018), uptake of MRI scanners dedicated for RT has been slow. Recent surveys carried out in Australia and Canada reported similar low rates of uptake, with only two (Batumalai et al 2016) dedicated MRI scanners for RT throughout the 37 independent RT providers in Australia (The Royal Australian and New Zealand College of Radiologists 2017) and four (Campbell et al 2018) systems in the 57 RT departments in Canada (Canadian Association of Radiation Oncology 2018). A recent marketing survey on the uptake of MRI on a per patient basis showed that across the USA in 2017, 24\% of radiotherapy treatment courses were planned with MRI as part of their treatment (IMV 2018) up from $12 \%$ in 2010. In 2018, an internal survey at Liverpool Cancer Therapy Centre, 
Sydney Australia with a dedicated scanner found that $32 \%$ of all RT patients received MRI (Liney 2018).

As a response to the increasing evidence of the benefit of MRI for treatment planning, the Institute of Physics and Engineering in Medicine (IPEM) have commissioned a working party to review the current practice of MRI in EBRT planning in the UK and to provide guidance on its use. The first task of this working party was to undertake a survey of the use of MRI in EBRT in the UK, the results of which are reported here. The specific aims of the UK survey were to: understand current practice of the use of MRI for EBRT treatment planning; investigate how MRI is currently used and managed; and identify knowledge gaps in the field. The results of this survey will be used to inform guidance on the use of MRI for EBRT treatment planning in the UK. This survey considered the use of MRI for photon EBRT treatment planning. Proton therapy, Gamma Knife, intraoperative RT and brachytherapy were considered specialist treatments and thus beyond the scope of this work.

\section{Method}

A survey was developed by a nine member, interdisciplinary IPEM working party tasked with producing guidelines on the use of MRI in EBRT treatment planning. The survey was designed with the intention that it would be most effectively completed by an interdisciplinary group at each institution to capture a range of aspects of clinical use. The survey comprised of 10 sections:

1. MRI access

2. Clinical sites in which MRI is used for EBRT treatment planning

3. MRI equipment

4. MRI pulse sequence details

5. MRI to CT registration

6. MRI commissioning and quality assurance (QA)

7. MRI safety

8. Workflow, staffing and training

9. Barriers to implementation of MRI for EBRT planning

10. Future applications of MRI

The Jisc Online Surveys platform (https://www.onlinesurveys.ac.uk/, Jisc, Bristol, UK) was used to create the survey (which is displayed in supplementary data in appendix 1). This facilitated electronic distribution, online response review and the ability to download the complete dataset for offline analysis. The survey was validated through a pilot study at the institutions represented in the Working Party to ensure that it could be completed in approximately 20 minutes. The survey was sent to 71 UK departments, comprising of 63 National Health Service (NHS) centres and eight private groups. An electronic link to the survey and a covering note was sent to heads of both RT Service and RT Physics in June 2018. A subsequent reminder email was sent to non-responders two weeks later. In order to 
maximise the participation rate, further encouragement was given to non-responding centres using personal contacts in July 2018. The survey was closed after a total of eight weeks. Responses from satellite centres (or linked sites in the case of private groups) were combined to give a single response.

Institutions were asked to estimate total patient numbers per month who received MRI as part of their RT planning. For NHS England centres these figures were used to estimate the percentage of RT patients per clinical site receiving MRI scans as part of their treatment planning. This was possible as Public Health England report the total number of RT treatment episodes per clinical site (National Cancer Registration and Analysis Service 2017). Within the UK the NHS management is split between the 4 countries and NHS for the other countries do not report these figures. The following assumptions were made: 1) annual number of episodes per disease site in England were taken as reported by Public Health England in 2016/2017 and was only reported for adults; 2) estimated number of patients per month receiving MRI scans for EBRT planning purposes for all centres in England, as reported in the survey, were multiplied by 12 to get an annual figure; 3) estimated annual figures were adjusted for total response rate in England (88\%) assuming that the distribution of throughput in the responding centres was representative of that in all centres.

The choice of MRI pulse sequences varied between institutions for each of the tumour sites. Due to the wide range of sequences used, and vendor-specific naming conventions, sequences have been summarised by weighting and acquisition method, specifically as: T1weighted (T1w) or T2-weighted (T2w); 2D or 3D; whether contrast agent was included; and whether fluid or fat suppression was used. Only tumour sites which were acquired at a minimum of five centres were included for this analysis, namely: brain, head and neck, spine, prostate, gynaecological, liver and rectum/anus. Multiple responders specified the use of diagnostic sequences for MR treatment planning.

The terminology for MRI scanners dedicated to RT treatment planning is ill defined but they are often referred to as MRI simulators or MRI sims in the literature. For clarity within this manuscript, the term 'dedicated MRI for $\mathrm{RT}^{\prime}$ ' is used and means an MRI scanner with such auxiliary equipment that patients can be scanned in the treatment position, for example, a flat-top couch and indexed immobilisation equipment.

\section{Results:}

An overall response rate of $87 \%$ of the centres contacted was achieved, with response rates of $89 \%$ and $75 \%$ for NHS and private centres respectively. It should be noted that one private provider replied on behalf of eight affiliated centres using unified MRI protocols. Some inconsistencies in data reporting were observed but no data cleaning was performed so results shown are as reported by centres. 


\section{Access to MRI}

It was reported that all responding centres use MRI for EBRT treatment planning in some form: either from a Picture Archiving and Communication System (PACS), potentially acquired in another institution ( $94 \%$ of responders); some form of direct access to an MRI scanner ( $69 \%$ of responders); or a combination of both. Of the centres that are using images from PACS for treatment planning, only $12 \%$ perform any image QA.

For the centres reporting some form of direct MRI access, the main access comes from radiology scanners within the same hospital, either on an ad hoc basis (52\% of responders), with dedicated RT sessions ( $26 \%$ of responders) or with both ad hoc and dedicated sessions on a radiology MRI scanner ( $16 \%$ of responders). Only two responders have a dedicated MRI scanner for RT. Finally, two responders have arrangements to have MRI scans acquired at a different institution.

\section{Clinical sites in which MRI is used for EBRT treatment planning}

The breakdown of the number of centres acquiring MRI for each clinical site is shown in Figure 1. The most common treatment sites where MRI is used in RT treatment planning were brain ( $52 \%$ of responders) and prostate (52\% of responders). Over $20 \%$ of responding centres acquire MRI for liver, spine, head and neck and gynaecological treatment sites. Less common treatment sites were rectum/anus, nodes, lung, pancreas, sarcoma and brachial plexus (all acquired at less than $15 \%$ of responding centres).

Nineteen percent of centres acquire MRI for brain patients in the treatment position. For the other most common clinical sites (where more than five centres acquire MRI scans) a mean of $49 \%$ of centres scan their patients in the treatment position, ranging from $38 \%$ for ano-rectal patients to $62 \%$ for liver patients.

Figure 1 also shows the breakdown of the number of centres acquiring MRI routinely, on an ad hoc basis, or for research purposes only. Some centres selected more than one option and in this case the centre was double or triple counted in figure 1 . The most common treatment site to routinely acquire MRI scans for treatment planning is the brain, with $75 \%$ of the 34 centres who acquire brain MRIs doing so routinely for all patients. Although prostate MRI acquisitions are also relatively common, only $22 \%$ of the 34 centres who reported acquiring MRI for prostate did so routinely for all their prostate patients. Pancreas, lung, sarcoma and brachial plexus are acquired at five or fewer centres, either on an ad hoc basis or solely for research purposes. 


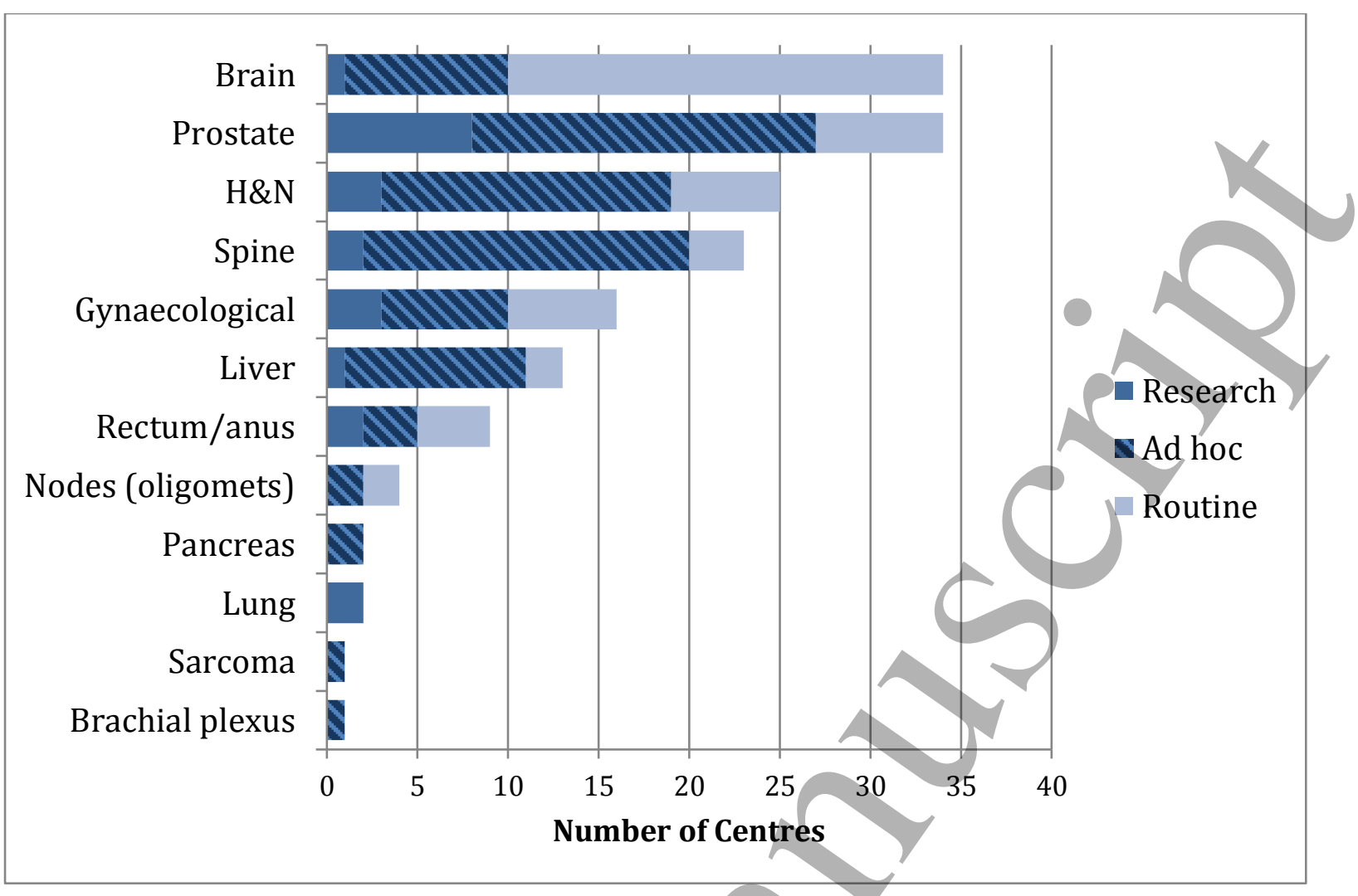

Figure 1 - Distribution of MRI acquisition category (acquired for Research, on an ad hoc basis or routinely for all patients) for all treatment sites reported

The breakdown of the number of patients scanned at each centre per month per treatment site is shown in Figure 2. Several centres that reported access to MRI did not report the actual numbers of patients scanned per month and hence the distributions in figures 1 and 2 differ. Although a substantial number of centres acquire MRI scans for treatment planning purposes, most centres acquire fewer than five patient scans per month for each treatment site. Only three centres scan more than 20 brain patients per month, three centres scan more than 20 prostate patients per month and one centre scans more than 20 gynaecological patients per month. 


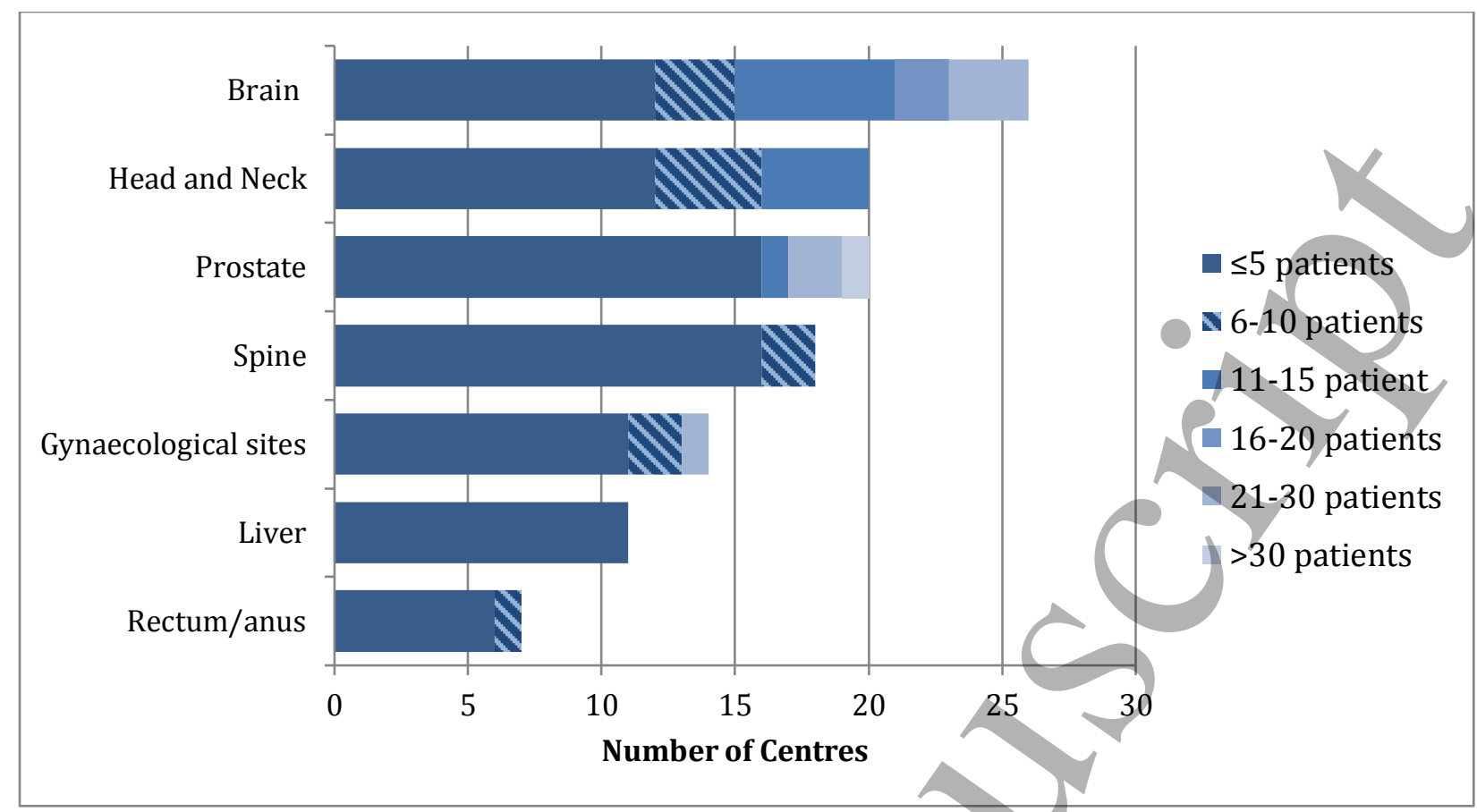

Figure 2 - Number of patients scanned at each centre per month for most common treatment sites (excluding sites acquired by fewer than 5 RT centres).

Estimates of the percentage of EBRT patients for different clinical sites treated in NHS England institutions that benefitted from an MRI scan as part of their treatment planning, can be seen in Table 1.

\begin{tabular}{|c|c|c|c|}
\hline Clinical site & $\begin{array}{c}\text { Number of episodes } \\
\text { in England 2016/17 }\end{array}$ & $\begin{array}{c}\text { Estimated number } \\
\text { of MRI } \\
\text { acquisitions in } \\
\text { England in } \mathbf{2 0 1 8}^{\mathbf{2}}\end{array}$ & $\begin{array}{c}\text { Estimated percentage } \\
\text { of patients receiving } \\
\text { planning MRI }\end{array}$ \\
\hline Brain & 3512 & 3198 & $91 \%$ \\
\hline Head \& Neck & 7029 & 1285 & $18 \%$ \\
\hline Prostate & 20278 & 1895 & $9 \%$ \\
\hline Gynaecological & 4073 & 910 & $22 \%$ \\
\hline Rectum/anus & & 368 & $6 \%$ \\
\hline All sites & 4168 & 7656 & $6 \%$ \\
\hline
\end{tabular}

Table 1 - Number of patients in NHS England receiving RT, estimated number having MRI acquired for $R T$ and estimated percentage of patients having MRI for EBRT for treatment planning per clinical site. Data not publically available outside of England. ${ }^{1}$ As reported by Public Health England on National Cancer Registration and Analysis Service website between 1/4/2016-31/3/17 (National Cancer Registration and Analysis Service 2017). Only clinical sites with data given on this report have been detailed here. ${ }^{2}$ As reported in this survey divided by 0.88 to adjust for response rate in England. ${ }^{3}$ Reported as colorectal by Public Health England. ${ }^{4}$ Total patients receiving RT for all sites was reported for 2015/2016 by Public Health England (Public Health England 2017). 


\section{MRI equipment}

The most common MRI scanner field strength that centres had access to was $1.5 \mathrm{~T}$ (63\% of responders). $23 \%$ of responders had access to both $1.5 \mathrm{~T}$ and $3 \mathrm{~T}$ MRI scanners, one centre reported access to a $3 \mathrm{~T} M R \mathrm{M}$ scanner alone and one centre reported access to a $0.35 \mathrm{TMRI}$ scanner.

Only $10 \%$ of responders use external RT lasers to setup patients on their MRI scanner. Three percent use lasers for all sites and six percent only use them when acquiring images for prostate and/or head and neck patients.

In order to acquire MRI in the treatment position $47 \%$ of responders reported using a flat top couch, with $34 \%$ having a commercial product and $13 \%$ manufacturing one in-house. Other common items of MRI equipment used for RT are commercial knee blocks ( $44 \%$ of responders) and coil bridges supports or holders (26\% of responders). Around $20 \%$ of centres reported using ankle/foot supports, masks and vacuum bags. Only seven percent of responders use RT specific radiofrequency (RF) coil arrangements.

\section{MRI sequence details}

Responses from centres regarding their use of different MRI sequences are detailed in Figure 3. In general, there was little indication provided of acquisition plane, but where mentioned the transverse plane was specified. It was reported that for all tumour sites a combination of $\mathrm{T} 1 \mathrm{w}, \mathrm{T} 2 \mathrm{w}, 2 \mathrm{D}$ and $3 \mathrm{D}$ sequences were acquired. A mixture of spin-echo (SE) and gradient echo (GE) sequences are used at institutions. There was wide variation in sequence choice with institutions reporting the use of combinations of sequences.

The responses show that fat suppression techniques are acquired in head and neck, spine, prostate and liver patients. Fat suppression techniques included: inversion recovery (IR) based techniques such as short tau IR (STIR) and spectral pre-saturation with IR (SPIR), frequency selective saturation and Dixon-based techniques (Del Grande et al 2014). Fluid suppression was acquired in the brain with $20 \%$ of responders using the FLAIR (fluid attenuated inversion recovery) sequence (Saranathan et al 2017).

Contrast agent was used for all clinical sites and was most common for brain imaging with $60 \%$ of centres using contrast for their brain patients. Imaging at multiple time points following contrast administration was noted for liver patients. DWI, which is sensitive to the free Brownian motion of water molecules in tissues (Malayeri et al 2011), was acquired for $\mathrm{RT}$ treatment planning in prostate and rectum/anus cancer patients.

Centres reported that MR images were acquired for gynaecological (20\%) and prostate (7\%) treatment planning in the presence of hip replacements to help improve delineation. In 
addition, $\mathrm{T} 2 *$ weighted sequences, which are sensitive to magnetic field inhomogeneities, were used to identify fiducial markers in prostate patients at $11 \%$ of institutions.

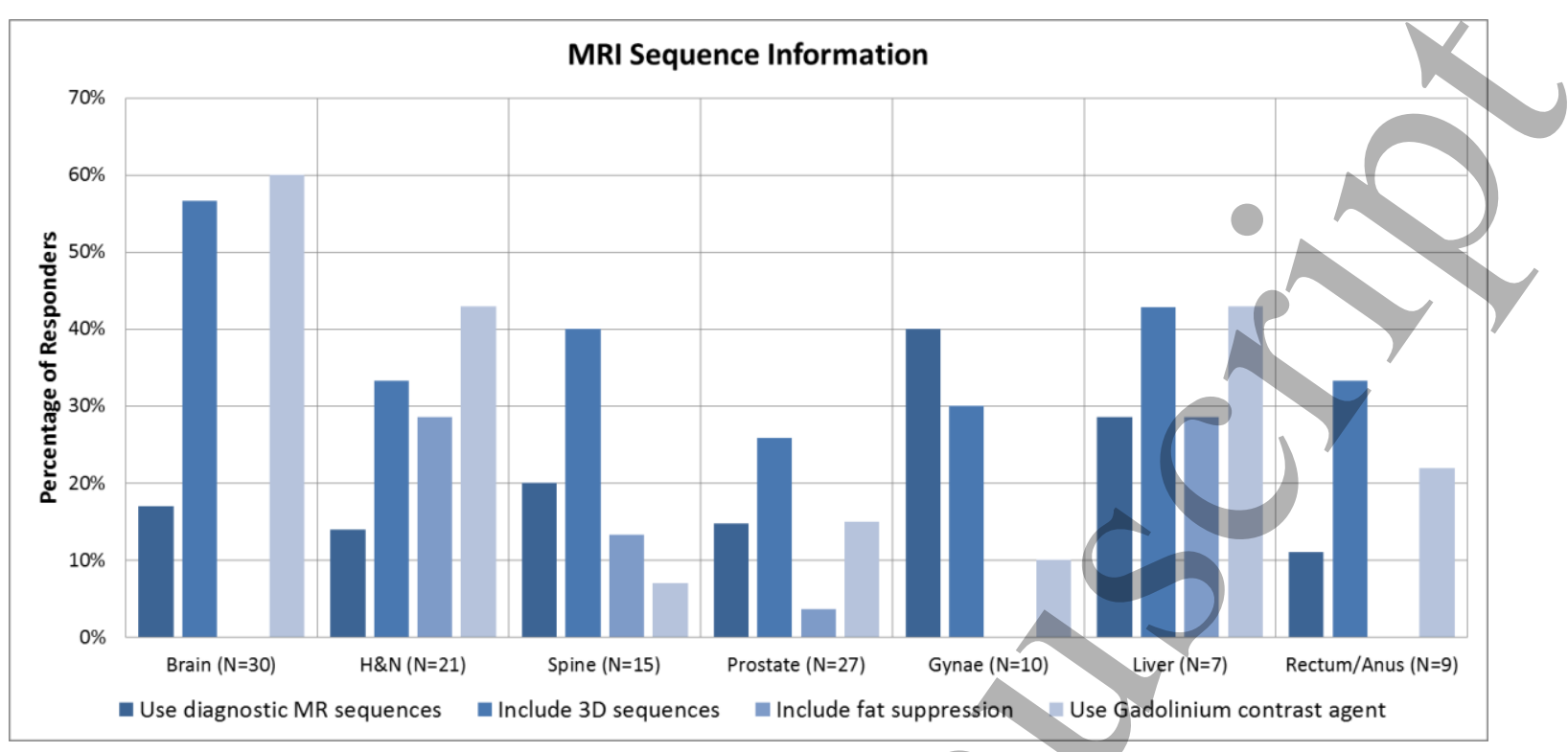

Figure 3 - MR sequence details for sequences which were common across the majority of tumour sites. The $N$ represents the number of responses obtained for each tumour site.

\section{MRI to CT registration}

For MRI to CT registration for RT treatment planning, 69\% of responders (all centres who have some dedicated MRI access) reported using rigid registration and $11 \%$ of responders use deformable image registration. Of the centres using deformable registration: two percent are using it for liver only, two percent for head and neck only, three percent reported to be in the commissioning process and five percent are using it for head and neck patients in a research only capacity. Overall, only two centres reported using deformable image registration clinically.

A variety of tests were identified for the commissioning of software used for MRI to CT registration. These tests and the number of centres which carry them out are summarised in table 2 . The most common test reported was qualitative assessment of patient registrations (39\% of responders), followed by assessment of checkerboard, overlap on phantoms and patients (26\% of responders) and quantitative assessment of landmark alignment (15\% of responders). One centre used a free-text entry box to report the use of a third-party service in commissioning of MRI to CT registration and one centre responded that they use "comparison versus an expert".

\section{Commissioning tests}

\section{Reported access to MRI}




\begin{tabular}{|c|c|c|c|c|c|}
\hline reported & $\begin{array}{c}\text { No } \\
\text { access }\end{array}$ & Ad hoc & $\begin{array}{l}\text { Dedicated } \\
\text { access }\end{array}$ & $\begin{array}{c}\text { Other } \\
\text { arrangements }\end{array}$ & $\begin{array}{c}\text { All } \\
\text { responding } \\
\text { centres }\end{array}$ \\
\hline & $(n=19)$ & $(n=22)$ & $(n=16)$ & $(n=5)$ & $(n=61)$ \\
\hline $\begin{array}{l}\text { Quantitative assessment of } \\
\text { physical phantom } \\
\text { registrations }\end{array}$ & 4 & & & & \\
\hline $\begin{array}{l}\text { Quantitative assessment of } \\
\text { digital phantom registrations }\end{array}$ & 3 & 4 & 1 & & \\
\hline $\begin{array}{c}\text { Quantitative assessment of } \\
\text { contours on registered } \\
\text { images }\end{array}$ & 1 & 3 & 2 & & 6 \\
\hline $\begin{array}{l}\text { Quantitative assessment of } \\
\text { landmark alignment (target } \\
\text { registration error) }\end{array}$ & 4 & 5 & & & 9 \\
\hline $\begin{array}{l}\text { Qualitative assessment of } \\
\text { patient registrations }\end{array}$ & 5 & 10 & 7 & 2 & 24 \\
\hline $\begin{array}{c}\text { Assessment of Jacobian } \\
\text { determinant }\end{array}$ & & & & & 0 \\
\hline $\begin{array}{c}\text { Assessment of deformation } \\
\text { map }\end{array}$ & & 1 & & & 1 \\
\hline $\begin{array}{c}\text { Consistency, transitivity } \\
\text { measurements }\end{array}$ & & & & & 3 \\
\hline $\begin{array}{l}\text { Assessment of checkerboard, } \\
\text { overlap on phantoms, } \\
\text { patients }\end{array}$ & 5 & & 4 & 1 & 16 \\
\hline End to end tests & 2 & 3 & 1 & & 6 \\
\hline Third party service & & & & 1 & 1 \\
\hline Comparison versus expert & & & & 1 & 1 \\
\hline
\end{tabular}

Table 2 - The different tests carried out by centres when commissioning MR to CT registration software broken down by the reported access to MRI at each centre. Centres with no access to MRI may take images directly from PACS for use during treatment planning. Centres with other arrangements include service level agreements or access to privately owned MRI scanners on NHS premises.

Of the centres providing details of using MRI to CT registration, $84 \%$ do no quantitative assessment of image registration on a per patient basis and $14 \%$ do some form of quantitative assessment (one centre did not submit an answer). Of the centres using MRI to $\mathrm{CT}$ registration, seven percent perform quantitative assessment of image registration only if it fails a qualitative test and seven percent of those using MRI to CT registration perform a quantitative assessment of every image registration. 
In addition, of the centres using MRI to $C T$ registration, centres with greater access to MRI through dedicated RT sessions are more likely to undertake quantitative assessment (4/11) compared to those with ad hoc slots on a radiology scanner (2/15).

\section{MRI commissioning and QA}

In total, $46 \%$ of responders provided information on test objects/phantoms that they used for QA purposes. From these, 10/28 sites reported no access to test objects specific to addressing the RT planning workflow. The test objects reported can be seen in table 3 .

\begin{tabular}{|c|c|c|c|}
\hline & Test Objects & Manufacturer & $\begin{array}{l}\text { Number } \\
\text { of sites }\end{array}$ \\
\hline \multirow{5}{*}{ 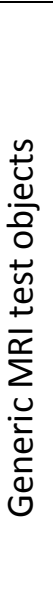 } & $A C R$ & $\begin{array}{c}\text { Newmatic Medical, Grand Rapids, } \\
\text { Michigan, USA }\end{array}$ & 13 \\
\hline & $\begin{array}{c}\text { Manufacturer's own test } \\
\text { objects }\end{array}$ & & 7 \\
\hline & Eurospin & Ultrasound Enterprises LTD, West & 1 \\
\hline & MagNET & n.a. & 1 \\
\hline & MagIQ Leeds Test Objects & $\begin{array}{c}\text { Leeds Test Objects, North } \\
\text { Yorkshire, UK }\end{array}$ & 1 \\
\hline \multirow{9}{*}{ 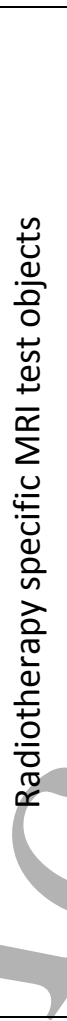 } & In-house distortion test object & n.a. & 9 \\
\hline & $\begin{array}{c}\text { CIRS large field of view } \\
\text { distortion }\end{array}$ & CIRS, Norfolk VA, USA & 3 \\
\hline & MagPhan RT & $\begin{array}{l}\text { The Phantom Laboratory, Greenwich } \\
\text { NY, USA }\end{array}$ & 3 \\
\hline & CIRS MRI linac dynamic & CIRS, Norfolk VA, USA & 2 \\
\hline & Quasar MRID 3D & $\begin{array}{l}\text { Modus Medical Devices Inc, } \\
\text { London ON, Canada }\end{array}$ & 2 \\
\hline & LAP Aquarius phantom & Lap Laser, Lueneburg, Germany & 2 \\
\hline & Grade phantom & $\begin{array}{l}\text { Spectronic Medical AB, Helsingborg, } \\
\text { Sweden }\end{array}$ & 2 \\
\hline & $\begin{array}{l}\text { CIRS MRI distortion phantom } \\
\text { for SRS }\end{array}$ & CIRS, Norfolk VA, USA & 1 \\
\hline & $\begin{array}{l}\text { STEEV end-to-end verification } \\
\text { phantom patient }\end{array}$ & CIRS, Norfolk VA, USA & 1 \\
\hline
\end{tabular}




\begin{tabular}{|c|c|c|}
\hline Quasar GRID 3D & $\begin{array}{c}\text { Modus Medical Devices Inc, London } \\
\text { ON, Canada }\end{array}$ & 1 \\
\hline
\end{tabular}

Table 3 - The make and number of test objects reported to be in use in the UK for assessing MRI scanners for EBRT.

In terms of the frequency of MRI QA specifically for RT purposes: $59 \%$ of responders provided no details; three percent indicated that they do not perform any additional QA for RT; two percent reported unknown arrangements with a 3rd party; and, three percent reported other arrangements, presumed not to fit in with the survey. From the 21 responders who provided information on testing frequency, "at commissioning" was the most common answer for the following tests: large FOV distortion (86\%); small FOV distortion (76\%); image quality (67\%); laser positioning (38\%); couch flatness (33\%); couch movement (29\%); and, 4D tests (10\%). The laser positioning test is the only one reported to occur more frequently on at least a monthly or quarterly basis. Table 4 lists the MRI QA commissioning tests reported by centres broken down by the type of MRI access they have. 


\begin{tabular}{|c|c|c|c|c|c|}
\hline \multirow{3}{*}{$\begin{array}{l}\text { Commissioning tests } \\
\text { reported }\end{array}$} & \multicolumn{5}{|c|}{ Reported access to MRI } \\
\hline & $\begin{array}{c}\text { No } \\
\text { access }\end{array}$ & $\begin{array}{l}\text { Ad hoc } \\
\text { access }\end{array}$ & $\begin{array}{l}\text { Dedicated } \\
\text { access }\end{array}$ & $\begin{array}{l}\text { Other } \\
\text { arrangements }\end{array}$ & $\begin{array}{l}\text { All } \\
\text { responding } \\
\text { centres }\end{array}$ \\
\hline & $(n=19)$ & $(n=22)$ & $(n=16)$ & $(n=5)$ & $(n=61)$ \\
\hline Image Quality & 4 & 2 & 1 & 0 & \\
\hline Small FOV Distortion & 2 & 3 & 2 & 0 & 7 \\
\hline Large FOV Distortion & 3 & 2 & 4 & 0 & 9 \\
\hline Laser Positioning & 0 & 1 & 1 & 0 & 2 \\
\hline Couch Movement & 1 & 2 & 0 & 0 & 3 \\
\hline Couch Flatness & 1 & 3 & 1 & 0 & 5 \\
\hline 4D tests & 1 & 0 & 1 & 0 & 2 \\
\hline
\end{tabular}

Table 4 - The different tests carried out by centres when commissioning an MRI scanner. Even sites with no regular access to MRI reported QA activity during commissioning.

\section{MRI safety}

The responses from centres regarding the identity of two MR safety-related staff roles, the MR Responsible Person and the MR Safety Expert, defined by the Medicines and Healthcare Products Regulatory Agency (MHRA, 2015) are detailed in table 5. The majority of centres reported additional safety features and practices over and above those which would be in place for a diagnostic scanner (see table 6).

\begin{tabular}{|c|c|c|c|c|}
\hline \multirow{2}{*}{ Staff group } & \multicolumn{2}{|c|}{ MR Responsible Person } & \multicolumn{2}{c|}{ MR Safety Expert } \\
\cline { 2 - 5 } & $\begin{array}{c}\text { No. } \\
\text { centres }\end{array}$ & $\begin{array}{c}\text { \% responders } \\
\text { with MRI for RT }\end{array}$ & $\begin{array}{c}\text { No. } \\
\text { centres }\end{array}$ & $\begin{array}{c}\text { \% responders } \\
\text { with MRI for RT }\end{array}$ \\
\hline Diagnostic Radiographer & 28 & $65 \%$ & 3 & $7 \%$ \\
\hline MRI physicist & 5 & $12 \%$ & 25 & $58 \%$ \\
\hline Radiologist & 4 & $9 \%$ & 0 & $0 \%$ \\
\hline Therapy radiographer & 2 & $5 \%$ & 0 & $0 \%$ \\
\hline RT physicist & 1 & $2 \%$ & 0 & $0 \%$ \\
\hline Diagnostic physicist & 1 & $2 \%$ & 5 & $12 \%$ \\
\hline $\begin{array}{c}\text { Varies by scanner, various } \\
\text { owners outside department }\end{array}$ & 1 & $2 \%$ & 3 & $7 \%$ \\
\hline 3rd party, unknown staff & 1 & $2 \%$ & 0 & $0 \%$ \\
\hline group & & & & \\
\hline
\end{tabular}




\begin{tabular}{|l|l|l|l|l|}
\hline Don't know & 0 & $0 \%$ & 3 & $7 \%$ \\
\hline
\end{tabular}

Table 5 - Staff groups for MR safety-related roles.

\begin{tabular}{|c|c|c|}
\hline Safety feature & $\begin{array}{c}\text { No. } \\
\text { centres }\end{array}$ & $\begin{array}{c}\text { \% responders } \\
\text { with MRI for RT }\end{array}$ \\
\hline Policies, arrangements & 28 & $65 \%$ \\
\hline Training & 22 & $12 \%$ \\
\hline $3 \mathrm{mT}(30 \mathrm{G})$ line marked on the floor & 5 & $5 \%$ \\
\hline Ferromagnetic detectors & 2 & $2 \%$ \\
\hline Field maps and profiles available in the control \\
room
\end{tabular}

Table 6-Safety features present, in addition to those in place for a diagnostic MR scanner.

\section{Workflow, staffing and training}

The majority of responders (88\%) reported that the responsibility of imaging patients was led by diagnostic radiographers. However, a substantial portion of responders (56\%) indicated that diagnostic radiographers were supported by therapy radiographers in patient setup. This collaborative workflow was supported by education provided to MRI radiographers (about the specific imaging and positioning needs of RT), through a variety of methods (Table 7). Alternatively, in order to assist MRI radiographers, it was also was reported that therapy radiographers who were present for MRI acquisitions undertook education in MRI safety, and screening through a mix of local induction and formal programs of study. Training and education for these enhanced roles for both therapy and diagnostic radiographers were undertaken through a mix of local induction and formal programs of study as illustrated in table 8.

\begin{tabular}{|c|c|c|}
\hline Type of Training/Education & $\begin{array}{c}\text { Number of Centres } \\
\text { Using Method }\end{array}$ & $\begin{array}{c}\text { Percentage of 43 centres } \\
\text { with access to MRI in RT }\end{array}$ \\
\hline Hands-on awareness from therapy radiographers & 1 & $2 \%$ \\
\hline Imaging needs for RT planning overview & 23 & $53 \%$ \\
\hline Observation of CT acquisition for patient positioning & 7 & $15 \%$ \\
\hline Specific setup and protocols on a per site basis & 2 & $5 \%$ \\
\hline Use of a single imaging isocentre for multiple sequences & 2 & $5 \%$ \\
\hline Use of RT lasers & 3 & $7 \%$ \\
\hline
\end{tabular}

Table 7-RT-specific Training and Education provided for MR Radiographers working on a dedicated $M R I$ scanner for $R T$. 


\begin{tabular}{|c|c|c|}
\hline Type of Training/Education & $\begin{array}{c}\text { Number of Centres Using } \\
\text { Training/Education Method }\end{array}$ & $\begin{array}{c}\text { Percentage of 43 centres with } \\
\text { access to MRI in RT }\end{array}$ \\
\hline Dedicated time shadowing in MRI & 8 & $19 \%$ \\
\hline External MRI courses & 2 & $5 \%$ \\
\hline In house tutorials & 18 & $42 \%$ \\
\hline Local work book activities & 6 & $14 \%$ \\
\hline MRI safety & 17 & $40 \%$ \\
\hline MRI screening & 11 & $26 \%$ \\
\hline Recognised postgraduate MRI Modules & 3 & $7 \%$ \\
\hline Study days & 4 & $9 \%$ \\
\hline
\end{tabular}

Table 8 - Type of MRI-specific Training and Education Provided for Therapy Radiographers working on a dedicated MRI scanner for RT.

In terms of using the images for treatment planning, responding centres indicated a collaborative working practice with all except one reporting that contouring was led by a clinical oncologist. It was reported that the oncologist had support from: dosimetrists $(40 \%$ of centres), radiologists ( $30 \%$ of centres), radiographers ( $23 \%$ of centres) and physicists (four percent of centres).

The majority of MRI physics support available for setting up a new service for MRI in RT was reported to come from MRI radiology teams in an ad hoc fashion either locally or provided from a different hospital ( $37 \%$ and $19 \%$ of responders respectively), or in the form of local RT physicists with some MRI education and experience ( $26 \%$ of centres responding). It was reported that $23 \%$ of responders reported that they had no MRI physics support.

\section{Barriers to implementation of MRI for EBRT planning}

Eighty-four percent of responders indicated the greatest challenge to incorporating $M R I$ in the EBRT pathway was the lack of access to MRI. Finance also played a significant role in limiting the use of MRI in EBRT, with 33\% of centres reporting that the lack of a RT MRI tariff and insufficient funding for staff and equipment as barriers to adoption of MRI in RT planning. Further challenges reported by $27 \%$ of centres include the gaps in knowledge and a lack of local support. Free text comments highlighted that some of these issues also resulted in challenges in strategic planning to improve MRI access within EBRT.

\section{Future applications of MRI}

Table 9 details the responses from centres about the anticipated role of MRI in EBRT at their institution within the next five years. There is an interest in increasing the role of MRI in EBRT in the UK: $37 \%$ of responders plan on implementing functional MRI; $38 \%$ intend on commissioning an MRI scanner dedicated for RT; $16 \%$ are planning for MRI-only RT; and, 
$10 \%$ are planning to commission an MRI linac. In terms of functional MRI, key issues that were highlighted in responses were: there is pressure to keep MRI slots as short as possible as well as a lack of knowledge of how to include functional information into the treatment planning process.

\begin{tabular}{|c|c|c|c|c|}
\hline & $\begin{array}{c}\text { Functional MRI } \\
\text { (e.g. DCE/DWI) }\end{array}$ & $\begin{array}{c}\text { MRI scanner } \\
\text { dedicated for RT }\end{array}$ & $\begin{array}{c}\text { MRI-only RT } \\
\text { planning }\end{array}$ & MRI linac \\
\hline $\begin{array}{c}\text { Plan to } \\
\text { Currently use }\end{array}$ & $15 \%$ & $3 \%$ & $0 \%$ & $3 \%$ \\
\hline $\begin{array}{c}\text { use/commissioning } \\
\text { within five years }\end{array}$ & $37 \%$ & $\begin{array}{c}38 \%(27 \% \text { in } \\
\text { addition to } \\
\text { current MRI } \\
\text { provision and } \\
11 \% \text { as a } \\
\text { replacement) }\end{array}$ & $16 \%$ & $10 \%$ \\
\hline $\begin{array}{c}\text { No intention to use } \\
\text { within five years }\end{array}$ & $21 \%$ & $48 \%$ & $84 \%$ & $87 \%$ \\
\hline Don't know & $32 \%$ & $14 \%$ & $0 \%$ & $0 \%$ \\
\hline
\end{tabular}

Table 9 - Future plans for the role of MRI for EBRT in their institution, all results shown are percentages of responders. DCE - dynamic contrast enhanced and DWI-diffusion weighted imaging.

\section{Discussion}

It has been widely reported that MRI has an important role in planning of EBRT (Cancer Research UK 2015, The Royal College of Radiologists 2017, Schmidt and Payne 2015). Specifically, MRI delineation has been shown to reduce toxicity rates for prostate treatments both with a standard fractionation (Sander et al 2014) and when hypofractionated (HYPRO trial) (Wortel et al 2017). A recent Independent Cancer Taskforce stated not only that the greatest improvements in treatments over the next decade are likely to be imaging based, but also that approximately 15-20 dedicated MRI scanners for RT should be funded by an NHS England national RT capital fund to facilitate the benefits of MRI for EBRT planning (Cancer Research UK 2015). Furthermore, the Royal College of Radiologists (RCR) recently reported that MRI is beneficial for RT volume definition and that a dedicated treatment position MRI will give improved results compared to a registered diagnostic MRI scan (The Royal College of Radiologists 2017).

Although all responding centres used MRI in some capacity for EBRT treatment planning, only two UK centres indicated they have dedicated MRI scanners for RT, which is lower than that reported in Australia and Canada (Batumalai et al 2016, Campbell et al 2018). Moreover, in the UK, the use of MRI is limited in most centres, with over $75 \%$ of centres undertaking fewer than five patient scans per month for prostate, spine, liver, gynaecological sites and anal/rectal cancer patients. Based on the responses to this survey, we estimate that in England (data not publicly available for the rest of the countries in the UK) $91 \%$ of brain patients undergo MRI as part of their EBRT treatment planning, this figure 
is much lower at only $18-22 \%$ for head and neck and gynaecological patients. Despite the reduction in toxicity discussed in the literature when MRI is used to guide radiotherapy in the prostate (Wortel et al 2017, Sander et al 2014), less than ten percent of prostate patients in England have MRI included in their RT treatment planning. For all patients in England (data not publically available outside of England) it has been estimated that six percent of patients undergo MRI as part of their EBRT treatment planning which is lower than the $24 \%$ of radiotherapy treatment courses in the USA that are planned with MRI as part of their treatment (IMV 2018). Although this is not a direct comparison, it is clear that patients in England are not receiving MRI as routinely as in the USA. Furthermore, a higher figure (32\%) has been reported from a Centre in Australia (Liney 2018) with a dedicated MRI scanner for radiotherapy where there had been previously little MRI use.

This survey has revealed a number of issues around the use of MR in EBRT treatment planning that need to be addressed for the benefits of MRI to be widely realised for EBRT patients in the UK. Specifically, these issues relate to the diverse working practises across the UK resulting from a lack of consensus in the literature and no clear guidelines from professional bodies; and, barriers to access and funding.

Highlighting the lack of consensus that exists across the UK, the variety in choice of MRI sequences, commissioning and quality assurance of image registration, or MRI technology is reported. The choice of MR sequences used for treatment planning varied widely between tumour sites and institutions. A number of sites used diagnostic MR scan protocols, suggesting that those sequences may not be optimised for radiotherapy treatment planning.

A combination of spin-echo (SE) and gradient-echo (GE) based sequences were reported between tumour sites and institutions based on specific need e.g. GE sequences for depicting fiducial markers. The choice of 3D versus $2 \mathrm{D}$ sequence varied between tumour sites and institutions. The use of 3D sequences was greatest in the brain $1>50 \%$ of institutions), likely associated with the high isotropic spatial resolution that can be attained to assess fine details and the ability to produce multi-planar reconstructions (Paulson et al 2015). Differences in contrast between 2D and 3D sequences could be the reason for some variation in the sequence choice between institutions. Preference for $3 D$ sequences for brain and H\&N planning and 2D for prostate and cervix planning has been suggested in a recent consensus paper (Paulson et al 2016).

Contrast agent was most commonly used for brain, H\&N and liver MR imaging. However, the number of contrast enhanced scans reported is possibly underestimated as there was no presumption that diagnostic or PACS acquired scans used a contrast agent unless explicitly stated. The use of contrast agent for brain and H\&N MR treatment planning has been suggested (Paulson et al 2016) and is recommended for diagnostic MR imaging of the brain in NICE guidance (NICE 2018). 
2D and 3D radial acquisition techniques (Feng et al 2014, Pipe 1999), compressed sensing methodology (Lustig et al 2007) and fast sequences, were mentioned for treatment sites associated with motion, e.g. the liver and lungs. The use of MRI for prostate and gynaecological patients with hip prostheses suggests the inherent benefit of reducing large metallic artefacts over the tumour bed compared to CT when planning in the pelvis (Schmidt et al 2016). The use of DWI was small and varied across centres, with the greatest use being in the prostate ( $15 \%$ of institutions), potentially related to its use in the PI-RADS system (Weinreb et al 2016).

Quality assurance and commissioning of MRI scanners specifically for RT was reported to be variable and was highlighted in this survey by the test frequency variability of QA procedures with only $29 \%$ of institutions owning MRI QA test objects that address specific issues within the RT setting. The majority of centres are utilising MRI scans from PACS for use in EBRT planning, only $12 \%$ of these centres are performing any QA on the images to ensure their suitability for this purpose.

With regard to a lack of guidance from professional bodies, although various groups have reported their solutions to the use of MRI in EBRT (Liney and Moerland 2014, Paulson et al 2015) there is no consensus in the literature or clear guidelines from professional bodies on the topic, or in the case of image registration only beginning to be available. To overcome this, guidance by professional bodies in the literature (either nationally or internationally) would be of benefit to standardise practice. The AAPM TG132 report (Brock et al 2017) is currently the only published guidance on image registration, with no UK-specific equivalent available. Based on the results of this survey, it is clear that the TG132 recommendations on per-patient quantitative tests, or those specifically for deformable registration (Paganelli et al 2018a), have not yet been widely adopted into UK clinical practice.

There is some guidance on QA frequency for diagnostic radiology purposes (McRobbie and Semple 2017, ACR 2017, Jackson et al 2010); the MRI literature gives fairly detailed guidance to those performing quantitative measurements and rather more flexible approaches in diagnostic examinations (Friedman and Glover 2006, Delakis et al 2004). Paulson et al. proposed an ambitious programme of testing which may be perceived as onerous to most MRI sites working with MR-CT fusion to plan RT (Paulson et al 2015). This issue is the central difficulty in proposing testing schedules - even within a fairly focused group of users of MRI, such as the RT planning users, there are still a range of different needs to be considered. An added complication in the UK is that as the majority of MRI access is provided by radiology and their QA requirements are different to those of RT users (Glide-hurst et al 2016). In addition, time pressures on scanners in clinical use may prevent the development of very detailed QA programmes.

IPEM report 112 (McRobbie and Semple 2017) provides guidance on general MRI QA but lacks detailed guidance for specific RT applications of MRI. Quality assurance of such 
applications is explored without giving any substantial detail in IPEM report 81 (2nd edition) (Patel 2018).

Guidance is required to ensure that MRI acquired beyond the control of the RT department is appropriate to use for RT purposes. For images used via PACS taken from MRI scanners not under the control of RT, there is the possibility that acquisition parameters could be changed as is standard practice for MRI acquired for radiology. This may impact the suitability of MRI for RT, such as: orientation of acquisition, any parameters effecting geometric distortion and the application of vendor specific geometric distortion correction. Therefore, for MRI used for RT it is vital that MRI sequences are commissioned for their specific purpose and that checks are made to ensure that relevant acquisition parameters are not changed.

The variability of how centres access MRI and the lack of guidance either in the literature or by professional bodies is also evidenced in the varied interdisciplinary working practices are used to acquire, register, interpret and contour MR images among the 43 centres with access to MRI. Staffing models and training varied significantly for MRI acquisition for EBRT; and it is hypothesised that this is due to both. There is an indication that implementation of MRI for EBRT treatment planning in the UK requires an inter-disciplinary team approach. In terms of physics support, collaboration between radiology and RT is vital with the majority of support coming from radiology. Worryingly, almost one in four centres reported no MRI physics support. This could be addressed via further training, contracting in support, employing an MRI physicist or a mentoring/buddy scheme between hospitals. Although the staff education has been shown to be variable, a full assessment of educational needs and quality of existing programs across all staff groups has yet to be undertaken. This has prompted a response by the Society of Radiographers to provide guidance for Therapeutic Radiographers working in MRI for RT, developed jointly by the RT and MRI advisory groups of the college (Eccles 2018).

In the UK, the MHRA defines two roles with responsibility for MR safety: the MR Responsible Person and the MR Safety Expert (MHRA 2015). Although the MHRA doesn't stipulate the staff groups from which these roles should be filled, this survey demonstrates preferences from the responding centres for the MR Responsible Person to be a diagnostic radiographer (65\% of responders who had access to MRI for RT) and for the MR Safety Expert to be an MRI physicist (58\%). The choice of a diagnostic radiographer reflects the fact that most centres use diagnostic scanners to acquire MRI for RT purposes.

Although the principles of MRI safety are no different when MRI is used for radiotherapy treatment planning, rather than for diagnostic scanning, most centres apply additional safety measures. We can speculate that the reasons for this include the variety of staff groups involved in scanning and the use of patient positioning equipment. Staff involved in scanning patients for radiotherapy planning are often a mix of staff from radiology and radiotherapy departments. This may require additional policies, procedures and training to 
ensure safe working practices. The range of equipment that is required may be perceived as a hazard that requires extra safety measures, such as ferromagnetic detectors and marking to indicate the projectile zone.

Barriers including a lack of MRI access and funding are severely limiting, the responses reported in free text comments within the survey suggests many centres recognise the benefit of MRI for a wide range of patient treatment sites, but these issues limit the number of patients that centres are able to scan. In the NHS, there is no specific tariff or reimbursement for MRI examinations performed for RT planning. Radiotherapy for brain cancers are the exception: this is the most commonly acquired patient group with $91 \%$ of patients benefitting from MRI as part of their treatment planning, yet $46 \%$ of institutions acquire MRI for fewer than five patients per month. The higher uptake of MRI for EBRT planning in the brain is likely due to the common approach of utilising diagnostic scans where good image registration with planning CTs can be achieved using the skull for rigid alignment.

The main reported barriers to utilising MRI for EBRT in the UK are financial, specifically, a lack of MRI access and no tariff. It was reported in this survey that there was a severe shortage of available MRI scanners in many hospitals across the UK; and that a lack of tariff or reimbursement for MRI scans in RT makes building a business case for supporting the required capital and revenue costs challenging. This is in line with the Independent Cancer Taskforce findings in 2015 (Cancer Research UK 2015), which reported that it is becoming increasingly inefficient to use MRI facilities for both radiology and RT. Securing tariffs for MRI scans, as well as the proposed national capital fund proposed by the Taskforce to support the capital costs of MRI scanners for RT, is crucial to enable RT patients across the NHS to benefit from MRI guidance in their treatment plans. It would be of interest to compare the provision of MRI for EBRT in the UK to other healthcare settings with other funding models. Although this is beyond the scope of the survey presented here the authors have started this work by initiating the same survey in other countries with the aim of publishing this data in the future.

Based on the responses to this survey and the growing body of literature on MRI guided RT (Schmidt and Payne 2015), there is evidence of a trend towards including MRI in the EBRT planning pathway over the next five years in the UK. The greatest interest appears to be in dedicated MRI scanners for RT and functional MRI. To a lesser extent, there is interest in MRI-only RT planning and MRI-linacs, generally from more research active centres.

To address some of the issues highlighted in this survey, it is the intention of the IPEM working group who have authored this work to provide guidance. A further point to note is that whilst $39 \%$ of responders are planning for a new MRI scanner dedicated to RT, guidance for these centres on how to setup such a dedicated scanner would be useful, $48 \%$ of centres are not planning to purchase a new MRI scanner for RT. Therefore, to meet the needs of this $48 \%$ it is the intention of the IPEM working party to provide guidelines to also offer 
pragmatic advice on how to make best use out of the sessions that centres already have on a current MRI scanner.

\section{Conclusion}

The UK MRI in EBRT landscape has been comprehensively surveyed in 2018. Access to dedicated MRI for EBRT is limited and lower than reported in other countries, with only two dedicated MRI scanners for RT. It is also estimated that only six percent of all EBRT patients in England are benefiting from MRI in their RT planning which is lower than international figures where these data are available. Despite the evidence for reduced toxicity when utilising MRI during planning for prostate patients, only an estimated nine percent of those radiotherapy patients in England benefit from MRI-aided delineation. The main reasons given for the lack of MRI for EBRT treatment planning are financial: lack of access to MRI scanners and lack of tariff making business cases for MRI scanners dedicated for RT challenging. This survey has highlighted that collaboration between RT and Radiology departments is important throughout the UK as it was found that Radiology departments support RT in terms of both equipment and staff. Many aspects of MRI in EBRT have been implemented heterogeneously in part due to the range of access to MRI scanners but largely due to the lack of consensus in the literature or explicit guidance from professional bodies. Despite being covered in the literature, the following have been identified as knowledge gaps in RT: staffing models/training; QA of both MRI scanners and image registration; sequences and the complimentary use of anatomical and functional information. It is the intention of the IPEM working group to attempt to fill these knowledge gaps in a future report specifically offering guidance not only for those who intend to setup a new MRI for RT service on a dedicated MRI scanner, but also for centres to get the most out of limited access on current MRI scanners.

\section{Acknowledgment}

The authors would like to thank IPEM for supporting the working group and endorsing this survey. We would also like to thank all respondents to the survey, without the hard work from these centres the survey would not have been possible.

Data for this report is based in part on patient-level information collected by the NHS, as part of the care and support of cancer patients. The data is collated, maintained and quality assured by the National Cancer Registration and Analysis Service, which is part of Public Health England (PHE).

Dr Richard Speight and Dr Ben George are supported by a Cancer Research UK Centres Network Accelerator Award Grant (A21993) to the ART-NET consortium. Dr Cynthia Eccles is supported by the NIHR Manchester Biomedical Research Centre. Mr Michael Dubec is 
supported by CRUK via the funding to Cancer Research UK Manchester Centre: [C147/A18083] and [C147/A25254].

\section{References}

ACR 2017 American College of Radiology CT Accreditation Program. Testing Instructions

Batumalai V, Holloway L C, Kumar S, Dundas K, Jameson M G, Vinod S K and Delaney G P 2016 Survey of image-guided radiotherapy use in Australia J. Med. Imaging Radiat. Oncol. 61 394-401 Online: https://onlinelibrary.wiley.com/doi/abs/10.1111/17549485.12556

Beavis A W, Gibbs P, Dealey R A and Whitton V J 1998 Radiotherapy treatment planning of brain tumours using MRI alone Br. J. Radiol. 71 544-8

Benedict S H, Yenice K M, Followill D, Galvin J M, Hinson W, Kavanagh B, Keall P, Lovelock M, Meeks S, Papiez L, Purdie T, Sadagopan R, Schell M C, Salter B, Schlesinger D J, Shiu A S, Solberg T, Song D Y, Stieber V, Timmerman R, Tomé W A, Verellen D, Wang L and Yin F F 2010 Stereotactic body radiation therapy: The report of AAPM Task Group 101 Med. Phys. 37 4078-101

Brock K K, Mutic S, McNutt T R, Li H and Kessler M L 2017 Use of image registration and fusion algorithms and techniques in radiotherapy: Report of the AAPM Radiation Therapy Committee Task Group No. 132 Med. Phys. 44 e43-76 Online: https://aapm.onlinelibrary.wiley.com/doi/abs/10.1002/mp.12256

Campbell M, Erler D and D'Alimont L 2018 Understanding the Canadian landscape to guide practice change: MRI in radiation therapy 6 th $M R$ in $R T$ Symposium (Utrecht) $p 1$ Online: https://www.mrinrt2018.com/wp-content/uploads/2018/06/C9.pdf

Canadian Association of Radiation Oncology 2018 Canadian Association of Radiation Oncology Online: http://www.caro-acro.ca/patients/canadian-radiation-oncologycentres/

Cancer Research UK 2015 Achieving World Class cancer outcomes: Stratergy 2015 - 2020

Curran W J, Hackney D B, Blitzer P H and Bilaniuk L 1986 The value of magnetic resonance imaging in treatment planning of nasopharyngeal carcinoma Int. J. Radiat. Oncol. 12 2189-96 Online: http://www.sciencedirect.com/science/article/pii/0360301686900192

Delakis I, Moore E M, Leach M O and Wilde J P De 2004 Developing a quality control protocol for diffusion imaging on a clinical MRI system Phys. Med. Biol. 49 1409-22 Online: http://stacks.iop.org/0031-

9155/49/i=8/a=003?key=crossref.466ec2fcc859df0b763ba4ee87ddb16d

Eccles C 2018 Personal correspondence between C. Eccles with members of SCOR MRAG

Edmund J M and Nyholm T 2017 A review of substitute CT generation for MRI-only radiation therapy Radiat. Oncol. 12 1-15 Online: http://dx.doi.org/10.1186/s13014-016-0747-y 
Erler D, D'Alimonte L and Campbell M 2018 Opportunity Is Knocking: The Need to Responsively and Responsibly Integrate Therapeutic MRI into Radiation Therapy J. Med. Imaging Radiat. Sci. 49 16-7 Online: https://doi.org/10.1016/j.jmir.2017.12.006

Fallone B G 2014 The Rotating Biplanar Linac-Magnetic Resonance Imaging System Semin. Radiat. Oncol. 24 200-2 Online: http://dx.doi.org/10.1016/j.semradonc.2014.02.011

Feng L, Grimm R, Block K T obia., Chandarana H, Kim S, Xu J, Axel L, Sodickson D K and Otazo R 2014 Golden-angle radial sparse parallel MRI: combination of compressed sensing, parallel imaging, and golden-angle radial sampling for fast and flexible dynamic volumetric MRI Magn. Reson. Med. 72 707-17

Fransson A, Andreo P and Pötter R 2001 Aspects of MR Image Distortions in Radiotherapy Treatment Planning Strahlentherapie und Onkol. 177 59-73

Friedman L and Glover G H 2006 Report on a multicenter fMRI quality assurance protocol J. Magn. Reson. Imaging 23 827-39 Online: https://onlinelibrary.wiley.com/doi/abs/10.1002/jmri.20583

Giezen M, Kouwenhoven E, Scholten A N, Coerkamp E G, Heijenbrok M, Jansen W P A, Mast M E, Petoukhova A L and Struikmans H 2011 Magnetic Resonance Imaging-Versus Computed Tomography-Based Target Volume Delineation of the Glandular Breast Tissue (Clinical Target Volume Breast) in Breast-Conserving Therapy: An Exploratory Study Int. J. Radiat. Oncol. 81 804-11 Online: https://www.sciencedirect.com/science/article/pii/S0360301610009041

Glide-hurst C K, Low D A, Orton C G, Glide-hurst C K and Ph D 2016 MRI / CT is the future of radiotherapy treatment planning POINT / COUNTERPOINT MRI / CT is the future of radiotherapy treatment planning 110601 Online: http://dx.doi.org/10.1118/1.4894495

Del Grande F, Santini F, Herzka D A, Aro M R, Dean C W, Gold G E and Carrino J A 2014 FatSuppression Techniques for 3-T MR Imaging of the Musculoskeletal System RadioGraphics 34 217-33 Online: http://pubs.rsna.org/doi/10.1148/rg.341135130

IMV 20182018 Radiation therapy market summary report Online: https://imvinfo.com/advance-search/?report_categories\%5B\%5D=radiation-oncology

Jackson E, Bronskill M, Drost D, Och J, Pooley R, Sobol W and Clarke G 2010 AAPM report 100 - Acceptance Testing and Quality Assurance Procedures for Magnetic Resonance Imaging Facilities

Johnstone E, Wyatt J J, Henry A M, Short S C, Sebag-Montefiore D, Murray L, Kelly C G, McCallum H M and Speight R 2018 Systematic Review of Synthetic Computed Tomography Generation Methodologies for Use in Magnetic Resonance Imaging-Only Radiation Therapy Int. J. Radiat. Oncol. Biol. Phys. 100 199-217 Online: http://dx.doi.org/10.1016/j.ijrobp.2017.08.043

Keall P J, Barton M and Crozier S 2014 The Australian Magnetic Resonance Imaging-Linac Program Semin. Radiat. Oncol. 24 203-6 Online: http://dx.doi.org/10.1016/j.semradonc.2014.02.015 
Kupelian P and Sonke J-J 2014 Magnetic Resonance-Guided Adaptive Radiotherapy: A Solution to the Future Semin. Radiat. Oncol. 24 227-32 Online: https://www.sciencedirect.com/science/article/pii/S1053429614000307

Lagendijk, J J W, Raaymakers, B W, van Vulpen M 2014 The Magnetic Resonance ImagingLinac System Semin. Radiat. Oncol. 24 207-9

van de Lindt T N, Schubert G, van der Heide U A and Sonke J J 2016 An MRI-based midventilation approach for radiotherapy of the liver Radiother. Oncol. 121 276-80 Online: http://dx.doi.org/10.1016/j.radonc.2016.10.020

Liney G P 2018 Personal correspondence between G Liney and clinical staff at the Liverpool Cancer Therapy Centre Radiation Oncology Unit (Sydney Australia)

Liney G P and Moerland M A 2014 Magnetic Resonance Imaging Acquisition Techniques for Radiotherapy Planning Semin. Radiat. Oncol. 24 160-8 Online: https://www.sciencedirect.com/science/article/pii/S1053429614000319?via\%3Dihub

Liney G P, Owen S C, Beaumont A K E, Lazar V R, Manton D J and Beavis A W 2013 Commissioning of a new wide-bore MRI scanner for radiotherapy planning of head and neck cancer Br. J. Radiol. 86

Lustig M, Donoho D and Pauly J M 2007 Sparse MRI: The Application of Compressed Sensing for Rapid MR Imaging Magn. Reson. Med. 58 1182-95

Malayeri A A, El Khouli R H, Zaheer A, Jacobs M A, Corona-Villalobos C P, Kamel I R and Macura K J 2011 Principles and Applications of Diffusion-weighted Imaging in Cancer Detection, Staging, and Treatment Follow-up RadioGraphics 31 1773-91 Online: https://doi.org/10.1148/rg.316115515

McRobbie D and Semple S 2017 Quality Control and Artefacts in Magnetic Resonance Imaging - IPEM Report 112

Ménard C, Paulson E, Nyholm T, McLaughlin P, Liney G, Dirix P and van der Heide U A 2018 Role of Prostate MR Imaging in Radiation Oncology Radiol. Clin. North Am. 56 319-25 Online:

https://www.sciencedirect.com/science/article/pii/S0033838917301860?via\%3Dihub

Metcalfe P, Liney G P, Holloway L, Walker A, Barton M, Delaney G P, Vinod S and Tomé W 2013 The Potential for an Enhanced Role for MRI in Radiation-Therapy Treatment Planning Technol. Cancer Res. Treat. 12 429-46 Online:

http://journals.sagepub.com/doi/10.7785/tcrt.2012.500342

MHRA 2015 Safety Guidelines for Magnetic Resonance Imaging Equipment in Clinical Use Online:

https://assets.publishing.service.gov.uk/government/uploads/system/uploads/attach ment_data/file/476931/MRI_guidance_2015_-_4-02d1.pdf

Močnik D, Ibragimov B, Xing L, Strojan P, Likar B, Pernuš F and Vrtovec T 2018 Segmentation of parotid glands from registered CT and MR images Phys. Medica 52 33-41 Online: https://www.sciencedirect.com/science/article/pii/S1120179718304940 
Mutic S and Dempsey J F 2014 The ViewRay System: Magnetic Resonance-Guided and Controlled Radiotherapy Semin. Radiat. Oncol. 24 196-9 Online:

http://dx.doi.org/10.1016/j.semradonc.2014.02.008

National Cancer Registration and Analysis Service 2017

Pateints_in_reciept_of_radiotherpay_1_April_2016_and_31_Mar.xlsx Online: www.ncin.org.uk

NICE 2018 Br Brain tumours (primary) and br ain tumours (primary) and brain ain metastases in adults metastases in adults NICE guideline NICE Guidel. Online: https://www.nice.org.uk/guidance/ng99/resources/brain-tumours-primary-and-brainmetastases-in-adults-pdf-1837763558341

Paganelli C, Meschini G, Molinelli S, Riboldi M and Baroni G 2018a "Patient-specific validation of deformable image registration in radiation therapy: Overview and caveats" Med. Phys. 45 e908-22

Paganelli $C$, Whelan B, Peroni $M$, Summers $P$, Fast $M$, van de Lindt $T$, $J M$, Eiben B, Keall $P$ and Lomax T 2018b MRI-guidance for motion management in external beam radiotherapy: current status and future challenges Phys. Med. Biol. 63 TR03 Online: https://iopscience.iop.org/article/10.1088/1361-6560/aaebcf

Patel I 2018 Physics Aspects of Quality Control in Radiotherapy - IPEM Report 81, 2nd edition

Paulson E S, Crijns S P M, Keller B M, Wang J, Schmidt M A, Coutts G and van der Heide U A 2016 Consensus opinion on MRI simulation for external beam radiation treatment planning Radiother. Oncol. 121 187-92 Online:

http://dx.doi.org/10.1016/j.radonc.2016.09.018

Paulson E S, Erickson B, Schultz C and Allen LiX 2015 Comprehensive MRI simulation methodology using a dedicated MRI scanner in radiation oncology for external beam radiation treatment planning Med. Phys. 42 28-39 Online:

https://aapm.onlinelibrary.wiley.com/doi/abs/10.1118/1.4896096

Pipe J G 1999 Motion correction with PROPELLER MRI: Application to head motion and freebreathing cardiac imaging Magn. Reson. Med. 42 963-9

Pollard J M, Wen Z, Sadagopan R, Wang J and Ibbott G S 2017 The future of image-guided radiotherapy will be MR guided Br. J. Radiol. 9020160667 Online:

http://www.birpublications.org/doi/10.1259/bjr.20160667

Public Health England 2017 Radiotherapy activity across England Online: http://www.ncin.org.uk/view?rid=3426

Raaymakers B W, Lagendijk J J W, Overweg J, Kok J G M, Raaijmakers A J E, Kerkhof E M, van der Put R W, Meijsing I, Crijns S P M, Benedosso F, van Vulpen M, de Graaff C H W, Allen J and Brown KJ 2009 Integrating a 1.5 T MRI scanner with a $6 \mathrm{MV}$ accelerator: proof of concept Phys. Med. Biol. 54 N229-37 Online: http://stacks.iop.org/00319155/54/i=12/a=N01?key=crossref.54089f06f82576151c8b56c369d3f175

Rai R, Sidhom M, Lim K, Ohanessian L and Liney G P 2017 MRI micturating urethrography for 
improved urethral delineation in prostate radiotherapy planning: a case study Phys. Med. Biol. 62 3003-10 Online: http://stacks.iop.org/00319155/62/i=8/a=3003?key=crossref.825dd4b2a8d2c2d29d74f1ca3982547c

Sander L, Langkilde N C, Holmberg M and Carl J 2014 MRI target delineation may reduce long-term toxicity after prostate radiotherapy Acta Oncol. (Madr). 53 809-14

Saranathan M, Worters P W, Rettmann D W, Winegar B and Becker J 2017 Physics for clinicians: Fluid-attenuated inversion recovery (FLAIR) and double inversion recovery (DIR) Imaging J. Magn. Reson. Imaging 46 1590-600 Online: https://onlinelibrary.wiley.com/doi/abs/10.1002/jmri.25737

Schmidt M A, Panek R, Colgan R, Hughes J, Sohaib A, Saran F, Murray J, Bernard J, Revell P, Nittka M, Leach M O and Hansen V N 2016 Slice Encoding for Metal Artefact Correction in magnetic resonance imaging examinations for radiotherapy planning Radiother. Oncol. 120 356-62 Online: http://dx.doi.org/10.1016/j.radonc.2016.05.004

Schmidt M A and Payne G S 2015 Radiotherapy planning using MRI Phys. Med. Biol. 60 R323-61 Online: https://www.ncbi.nlm.nih.gov/pubmed/26509844

Shang L, Liu Z, Rong Y, Zhou T and Zuo L 2017 MRI in breast cancer radiotherapy in prone and supine positions Front. Biosci. 22 570-9

Stemkens B, Paulson E S and Tijssen R H N 2018 Nuts and bolts of 4D-MRI for radiotherapy Phys. Med. Biol. 6323 Online: http://iopscience.iop.org/article/10.1088/1361$6560 /$ aae $56 \mathrm{~d} / \mathrm{meta}$

The Royal Australian and New Zealand College of Radiologists 2017 The Royal Australian and New Zealand College of Radiologists Online: https://www.targetingcancer.com.au/treatment-centres/

The Royal College of Radiologists 2017 Radiotherapy target volume definition and peer review - RCR guidance Online: www.rcr.ac.uk

Voroney J P, Brock K K, Eccles C, Haider M and Dawson L A 2006 Prospective comparison of computed tomography and magnetic resonance imaging for liver cancer delineation using deformable image registration Int. J. Radiat. Oncol. Biol. Phys. 66 780-91

Weinreb J C, Barentsz J O, Choyke P L, Cornud F, Haider M A, Macura K J, Margolis D, Schnall M D, Shtern F, Tempany C M, Thoeny H C and Verma S 2016 PI-RADS Prostate Imaging Reporting and Data System: 2015, Version 2 Eur. Urol. 69 16-40 Online: http://dx.doi.org/10.1016/j.eururo.2015.08.052

De Wilde J, Price D, Curran J, Williams J and Kitney R 2002 Standardization of performance evaluation in MRI: 13 Years' experience of intersystem comparison Concepts Magn. Reson. 15 111-6 Online: https://onlinelibrary.wiley.com/doi/abs/10.1002/cmr.10012

Wortel R C, Heemsbergen W D, Smeenk R J, Witte M G, Krol S D G, Pos F J and Incrocci L 2017 Local Protocol Variations for Image Guided Radiation Therapy in the Multicenter Dutch Hypofractionation (HYPRO) Trial: Impact of Rectal Balloon and MRI Delineation on Anorectal Dose and Gastrointestinal Toxicity Levels Int. J. Radiat. Oncol. Biol. Phys. 
99 1243-52 Online: https://doi.org/10.1016/j.ijrobp.2017.07.044

\section{Supplementary material Appendix 1 - SEE PDF DOCUMENT}

